\title{
Jurisprudencia
}

\section{Intervención de la Facultad de Derecho y Ciencias Políticas de la Universidad de Ibagué en la demanda de inconstitucionalidad contra el artículo 223 de la Ley 906 de 2004. Sentencia C-480-20}

\author{
Sandra Bibiana Vargas Castro
}

Publicación: 30/07/2021

Para citar este artículo

\section{Vargas Castro, S. B. (2021). Intervención de la Facultad de Derecho y}

Ciencias Políticas de la Universidad de Ibagué en la demanda de incons-

titucionalidad contra el artículo 223 de la Ley 906 de 2004. Sentencia

C-480-20. Dos mil tres mil, 23, e325. https://doi.org/10.35707/

dostresmil/23325

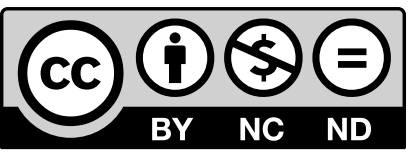


Las demandas de inconstitucionalidad hacen parte del ejercicio democrático mediante el cual el ciudadano acude a la jurisdicción constitucional, en busca de proponer por parte de la Corte el análisis de una norma que se acusa de contradecir la Constitución.

Las universidades del país son invitadas a participar en el trámite inicial que surte la demanda, con el propósito de proporcionar su interpretación jurídica entre la norma demandada y la Constitución Política. Este ejercicio previo a la decisión final de la Corte Constitucional se ha convertido en un espacio valioso de expresión de la voz académica en el contexto práctico de una decisión judicial.

El lector encontrará a continuación, el concepto proyectado por la profesora Sandra Bibiana Vargas Castro y presentado por Hernando A. Hernández Quintero, decano de la Facultad de Derecho y Ciencias Políticas, en representación de esta unidad académica en el trámite de la demanda de inconstitucionalidad de la norma dispuesta en el artículo 223 de la Ley 906 de 2004 "Por la cual se expide el Código de Procedimiento Penal". Esta controversia jurídica fue resuelta mediante la Sentencia C-480-20 que puede ser consultada aquí. 


\section{Concepto}

\section{De la demanda de inconstitucionalidad}

Los ciudadanos Andrés Felipe Vasco Ríos, Cristian Felipe Montoya Bermúdez y David Esteban Giraldo Calderón, solicitan a la honorable Corte Constitucional declarar la inconstitucionalidad de la disposición de la referencia, que ordena cuales objetos no susceptibles de registro. El mencionado artículo ordena lo siguiente:

No serán susceptibles de registro los siguientes objetos: 1 . Las comunicaciones escritas entre el indiciado, imputado o acusado con sus abogados. 2. Las comunicaciones escritas entre el indiciado, imputado o acusado con las personas que por razón legal están excluidas del deber de testificar. 3. Los archivos de las personas indicadas en los numerales precedentes que contengan información confidencial relativa al indiciado, imputado o acusado. Este apartado cobija también los documentos digitales, videos, grabaciones, ilustraciones y cualquier otra imagen que sea relevante a los fines de la restricción.

Respecto de los anteriores incisos no existe reparo alguno por parte de los accionantes, pero en relación con el parágrafo del mismo artículo, los demandantes afirman que se configura la inconstitucionalidad, ya que se excluye por parte del legislador a la persona que no tiene la calidad de autor de este beneficio, tal y como lo estipula el parágrafo de la siguiente manera:

Estas restricciones no son aplicables cuando el privilegio desaparece, ya sea por su renuncia o por tratarse de personas vinculadas como auxiliadores, partícipes o coautoras del delito investigado o de uno conexo o que se encuentre en curso, o se trate de situaciones que constituyan una obstrucción a la justicia. (Negrilla fuera del texto original).

Los accionantes consideran que lo resaltado en negrilla es inconstitucional en tanto que vulnera el derecho a la igualdad, derecho al debido proceso, derecho a la no autoincriminación y no incriminación de terceros y el derecho-deber del secreto profesional, todos estos derechos consagrados en la Constitución Política, en los artículos 13, 29, 33 y 74, respectivamente.

Respecto al derecho de la igualdad consagrada en el artículo 13 constitucional, los accionantes afirman que no existe justificación constitucional, que permita la discriminación en la aplicación del beneficio de que sus objetos no sean susceptibles de registro, a las personas que no tengan calidad de autor, es decir, a los coautores o partícipes (determinador, cómplice e intervinientes). Lo que constituye una situación más gravosa para estos últimos, en comparación con el autor del delito, que conlleva a que quienes son coautores nunca podrán obtener una pena mayor a la que se le pudiera imponer al autor del mismo delito, estarán siempre excluidos del mencionado beneficio gracias a la ley procesal, específicamente el parágrafo del artículo 233 del Código de Procedimiento Penal.

Precisan los demandantes, que no existe justificación racional y jurídica, de que el autor del delito pueda obtener el beneficio de la prohibición de los objetos no susceptibles a registro, 
mientras que los coautores se excluyen del mismo, teniendo en cuenta que estos últimos ostentan la calidad de autores, con la única diferencia de que se les determina coautores por la multiplicidad de sujetos activos.

Asimismo, los demandantes señalan, en relación con los determinadores, el artículo 30 de la Ley 599 de 2000 en donde se señala que los determinadores incurren en la misma sanción penal del autor, pero en todo caso se le excluye de la prohibición señalada en el artículo 223 del Código de Procedimiento Penal, sin que exista justificación jurídica alguna.

Finalmente, los accionantes aclaran, que independiente que una persona sea autor, coautor o partícipes (determinador, cómplice o interviniente) de un delito, todos comparten una calidad en común dentro del proceso penal y esta calidad consiste en que se les determine "indiciados, imputados o acusados" (dependiendo del momento procesal en que se encuentren) $y$, por lo tanto, no se puede realizar discriminación alguna en frente de los mismos y deben ser tratados como sujetos que gocen de los mismos derechos y garantías procesales.

Respecto al artículo 29 de la Constitución Política que señala el derecho al debido proceso, los accionantes afirman que se ve vulnerado el derecho de defensa (que de acuerdo con la jurisprudencia constitucional hace parte del derecho al debido proceso), toda vez, que a las personas que no son autores de un delito se les imposibilita el derecho de tener una defensa técnica y material, ya que de acuerdo con los demandantes:

Teniendo en cuenta que todos los sujetos del derecho penal mencionados son procesados, indiciados y demás, en todo plano jurídico, les cobija el derecho a la defensa técnica y material, la cual se vulnera al permitir que se configure, como elemento de prueba de descargo, las conversaciones y documentos con fines de comunicación que estos tengan con sus abogados y con las personas mencionadas en el artículo 33 de la Constitución Política. (p. 6).

En lo relacionado con el artículo 33 constitucional, que consagra el derecho a la no autoincriminación y no incriminación de terceros, los demandantes afirman que el parágrafo del artículo 223 del Código de Procedimiento Penal permite flagrantemente la vulneración al precepto constitucional, al permitir el registro de las comunicaciones entre el indicado, imputado o acusado con su cónyuge, compañero o parientes. Además, hacen alusión a jurisprudencia constitucional y tratados internacionales ratificados por Colombia, donde se ha establecido la prohibición absoluta de forzar declaraciones de las personas en contra de su cónyuge, compañero o parientes.

Y, finalmente, en lo que corresponde al derecho del secreto profesional consagrado en el artículo 74 de la Constitución Política, que señala la inviolabilidad del secreto profesional.

Intervención de la Facultad de Derecho y Ciencias Políticas de la Universidad de Ibagué en la demanda de inconstitucionalidad contra el artículo 223 de la Ley 906 de 2004. Sentencia C-480-20 
Los accionantes afirman:

El derecho de reserva profesional es una garantía que tienen las personas que buscan profesionales idóneos para ponerles de conocimiento ciertas circunstancias fácticas o acaecidas, con el fin de que se les preste sus servicios en la solución de los mismos, y en el ejercicio profesional, se debe guardar como secreto las informaciones conocidas, máxime cuando es la misma constitución en su artículo 73 que lo plasma (Hoja 9).

Por lo anterior, los demandantes traen a colación lo señalado por la Corte Constitucional, en donde se ha determinado que el secreto profesional tiene un alcance especial, ya que puede afectar o vulnerar el derecho a la defensa, y es por esa razón, que se ha señalado la inviolabilidad de las comunicaciones entre abogado defensor y su defendido, independiente de que sea autor, coautor o partícipe de una conducta punible.

\section{Concepto de la Facultad de Derecho y Ciencias Políticas de la Universidad de Ibagué}

En efecto, el artículo 223 del Código de Procedimiento Penal vigente señaló que no serán susceptibles de registro los siguientes objetos: (1) Las comunicaciones escritas entre el indiciado o acusado con sus abogados. (2) Las comunicaciones escritas entre el indiciado, imputado o acusado con las personas que por razón legal están excluidas de testificar. (3) Los archivos de las personas indicadas en los numerales precedentes que contengan información confidencial relativa al indiciado, imputado o acusado...

Como lo señala el demandante, el artículo citado vulnera el derecho a la igualdad, al no dar igual tratamiento a los coautores y copartícipes (cómplice, determinador) respecto de las garantías en el proceso penal, vulnerando la disposición Constitucional pregonada en el artículo 13 de la Constitución Política y artículo $4^{\circ}$ del Código de Procedimiento Penal que señala que “...es obligación de los servidores judiciales hacer efectiva la igualdad de los intervinientes en el desarrollo de la actuación procesal...”.

En la Sentencia C-221 de 1992, la honorable Corte Constitucional se refirió al alcance del principio de igualdad consagrado en el artículo 13 constitucional, de la siguiente forma:

Ese principio de la igualdad es objetivo y no formal; él se predica de la identidad de los iguales y de la diferencia entre los desiguales. Se supera así el concepto de la igualdad de la ley a partir de la generalidad abstracta, por el concepto de la generalidad concreta, que concluye con el principio según el cual no se permite regulación diferente de supuestos iguales o análogos y prescribe diferente formación a supuestos distintos. Con este concepto solo se autoriza un trato diferente si está razonablemente justificado. Se supera también, con la igualdad material, el igualitarismo o simple igualdad matemática.

Intervención de la Facultad de Derecho y Ciencias Políticas de la Universidad de Ibagué en la demanda de inconstitucionalidad contra el artículo 223 de la Ley 906 de 2004. Sentencia C-480-20 
Igualmente, señala el accionante que la redacción del artículo 223 del Código de Procedimiento Penal lesiona el debido proceso y el derecho de defensa de los sujetos no cobijados por la excepción prevista en el citado artículo respecto de los coautores y partícipes de la comisión de un delito, cuestión que no sucede con los autores, quienes no están obligados a relevar las conversaciones con su defensor, en su calidad de indiciados, imputados o acusados, así como las comunicaciones escritas entre estos y sus parientes, o los archivos que contengan información confidencial respecto de los mismos.

Recordemos que cuando el actual sistema procesal penal le da la categoría de sujetos procesales a los autores, coautores, y demás partícipes, los equipara en cuanto a los deberes y derechos o garantías en el proceso penal, sin que tengan distinción alguna en cuanto al ejercicio de esos derechos o garantías, razón por demás para declarar la inconstitucionalidad de la norma invocada.

El artículo 10 del Código de Procedimiento Penal señala:

Actuación procesal. La actuación procesal se desarrollará teniendo en cuenta el respeto a los derechos fundamentales de las personas que intervienen en ella y la necesidad de lograr la eficacia del ejercicio de la justicia (...) el juez de control de garantías y el de conocimiento estarán en la obligación de corregir los actos irregulares no sancionados con nulidad, respetando siempre los derechos y garantías de los intervinientes.

Fijémonos cómo dicho artículo no hace distinción en el tratamiento de los coautores y demás partícipes en las actuaciones en el proceso penal, como sí lo hace odiosamente el artículo 223 del estatuto procesal del cual hoy predican la inconstitucionalidad los demandantes, razón por la cual encontramos fundamento en sus peticiones.

De otra parte como bien se señala en la demanda, el actual parágrafo del artículo 223 del CPP lesiona gravemente el derecho a la no autoincriminación de los auxiliadores, coautores y demás partícipes en el proceso penal al obligarlos a revelar información privilegiada o de carácter secreta, esto es, conversaciones y documentos privados entre estos y sus defensores, lo que sin ninguna duda atenta contra el principio constitucional del artículo 33 de la carta magna que protege toda información que pueda provocar una autoincriminación por parte de los intervinientes en el proceso penal.

Igualmente, encontramos que la norma invocada no guarda el mismo espíritu del contenido del artículo 359 del Código de Procedimiento Penal, cuando nos señala en su inciso segundo:

En la Audiencia Preparatoria se inadmitirán los medios de prueba que se refieran a las conversaciones que haya tenido la Fiscalía con el imputado, acusado o defensor en desarrollo de manifestaciones preacordadas, suspensiones condicionales y aplicación del principio de oportunidad, a menos que el imputado, acusado o defensor consientan en ello.

Esta norma previendo la garantía al derecho de autoincriminación no solo no obliga a revelar las conversaciones o documentos entre quienes han sido vinculados al proceso penal, 
pues entre otras - el proceso penal acusatorio, no puede edificarse sobre esta información privilegiada de quien es sujeto activo del proceso penal- sino que tampoco hace la distinción entre autores y coautores, auxiliadores o partícipes, como si lo hace el artículo 223 del estatuto procesal, al quedar excluidos los coautores, auxiliadores o partícipes del beneficio de revelar sus documentos, de tal forma que esta información sea susceptible de registros.

En el mismo sentido la norma protege las conversaciones y documentos tenidos en cuenta al momento de realizar aceptaciones de cargos, negociaciones en el proceso penal (preacuerdos), o beneficiados al principio de oportunidad, en caso de no ser acogidos por los jueces y que sus asuntos continúen el trámite ordinario del proceso penal, a menos que los imputados, acusados o defensores consientan en ello, sin hacer diferencia alguna entre unos y otros de los intervinientes en el proceso penal, cuyo objeto se demanda.

El espíritu de la norma del artículo 223 del CPP, entra en contravía con otras normas legales como hemos señalado y con principios fundamentales pregonados por la Constitución Política de Colombia y por ello les asiste razón a los demandantes para que se declare la inconstitucionalidad del parágrafo del artículo 223 del actual Código de Procedimiento Penal (Ley 906 de 2004).

\section{Referencias}

Constitución Política de Colombia: Artículos 29 y 74.

Código de Procedimiento Penal: Artículos 10, 223, 359.

Sentencia No. C-221 de 1994. Corte Constitucional de Colombia.

\section{Bibliografía consultada}

López Medina, D. E. (2002). El derecho de los jueces. Bogotá, Colombia Legis-Uniandes, Facultad de Derecho. 